\title{
Menelusuri Potensi Fraud dalam Jaminan Kesehatan Nasional melalui Rekam Medis di Rumah Sakit
}

\section{Tracing Potential Fraud in National Health Insurance Through Medical Records in Hospitals}

\author{
Ida Sugiarti1凶, Imas Masturoh², Fery Fadly ${ }^{3}$ \\ 1,2,3Prodi D3 RMIK Poltekkes Kemenkes Tasikmalaya
}

\begin{abstract}
ABSTRAK
Latar Belakang: Akibat fraud, BPJS (Badan Penyelenggara Jaminan Sosial Kesehatan) harus membayar klaim lebih besar, sehingga terjadi kerugian negara. Salah satu bentuk fraud yang ditemukan di kelompok provider adalah upcoding. Data koding dan rekaman pelayanan kesehatan dalam rekam medis dapat digunakan sebagai deteksi fraud.

Tujuan: Menelusuri potensi fraud dalam rekam medis melalui telusur keakuratan kode diagnosis dan clinical pathway.

Metode: Pendekatan kuantitatif kualitatif. Jenis penelitian case study, kasus thypoid. Subjek penelitian ditentukan dengan purposive sampling. Sampel penelitian kuantitatif menggunakan berkas rekam medis. Metode pengumpulan data menggunakan lembar observasi dan indept interview. Analisis data kuantitatif dengan analisis deskriptif dan Analisa data kualitatif dengan analisis konten.

Hasil: Dari 87 dokumen, ketidaktepatan kode diagnosis 31,03\%, dengan presentase ketidaksesuaian tarif klaim $26,44 \%$. Terdapat berbagai penyebab upcoding diantaranya karena aturan pengkodean yang berbeda antara kode diagnosis berdasarkan ICD 10 dan kode untuk kepentingan klaim yang mengacu pada peraturan dari BPJS yang dituangkan dalam Berita Acara. 91,30\% ketidaksesuaian merupakan tarif klaim naik. Ketidaksesuaian clinical pathway paling banyak pada item tes widal dengan presentase $21.84 \%$.

Kesimpulan: Upcoding tidak selalu disebut fraud, harus ada unsur kesengajaan untuk mendatangkan keuntungan finansial. Upcoding dapat merubah klaim menjadi lebih tinggi. Keberadaan clinical pathway penting sebagai acuan tindakan pelayanan kesehatan.
\end{abstract}

Kata Kunci: upcoding; clinical pathway; fraud; BPJS; ICD

\section{ABSTRACT}

Background: The Health Social Security Administering Body has to pay more extensive claims due to fraud, resulting in state losses. One form of fraud found in the provider group is upcoding. Coding data and health records in medical records can be used as fraud detection.

Objective: Tracing potential fraud by tracing the accuracy of diagnostic codes and clinical paths in medical records.

Methods: A qualitative-quantitative approach with a case study, a typhoid case. The research subjects were selected by purposive sampling. Quantitative research samples are medical records. The instrument used an observation sheet and interview guidelines. Data collection with; observation and in-depth interviews. Quantitative data analysis is descriptive analysis and qualitative data is content analysis.

Results: From 87 documents, the diagnosis code was $31.03 \%$ inaccurate. with a claim rate mismatch percentage of $26.44 \%$. There are various causes of upcoding including the different coding rules between the diagnosis code based on ICD 10 and the code for claims purposes that refer to the regulations of the BPJS as outlined in the Minutes. $91.30 \%$ non-conformity represents an increased claim rate. The most clinical pathway discrepancies were in the widal test items with a percentage of $21.84 \%$.

Conclusion: Upcoding is not always called fraud, there must be an element of intent to bring financial gain. Upcoding can change the claim to be higher. Clinical pathways are essential as a reference for health service actions.

Keywords: upcoding; clinical pathway; fraud; BPJS; ICD

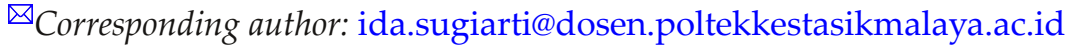

Diajukan 11 September 2021 Diperbaiki 14 Januari 2022 Diterima 9 Februari 2022

https://jurnal.ugm.ac.id/jkesvo Published online February 28, 2021 


\section{PENDAHULUAN}

Negara mengalami kerugian ketika BPJS Kesehatan harus mengganti biaya klaim lebih tinggi, akibat fraud (BPJS Kesehatan, 2015). Fraud atau perbuatan curang merupakan kesengajaan yang dilakukan dengan untuk mendapatkan keuntungan finansial sehingga berpotensi merugikan negara dan menyebabkan mutu pelayanan kesehatan menurun (Kemenkes, 2019), (Djasri, Rahma and Hasri, 2016). WHO memperkirakan perawatan kesehatan global tahunan adalah US \$ 5,7 triliun. Setiap tahun, 7,29\% dari itu, atau sekitar US \$ 415 miliar, hilang karena fraud (dan error)(Jones and Jing, 2011). Kasus fraud naik 83\% dari 2017, beberapa di antaranya terkait pengadaan, asuransi kesehatan, dan perjalanan (Ravelo, 2019).

Potensi bentuk fraud yang ditemukan di kelompok provider diantaranya adalah upcoding. Bentuk fraud lainnya inflated bills, service unbundling, no medical value dan standard of care (Djasri, Rahma and Hasri, 2016). Kajian tentang fraud di rumah sakit, menempatkan upcoding pada posisi teratas (KSI, 2016). Upcoding atau penulisan kode diagnosis yang berlebihanterdapat dalam rekam medis pasien.

Hasil penelitian terkait dengan kesalahan koding pada kasus gastroenteritis acute terdapat sebanyak 63 kasus (Karimah, Setiawan and Nurmalia, 2016). Hasil penelitian (Puspitasari and Kusumawati, 2017), didapat sebanyak 168 (33\%) merupakan kode yang tidak tepat. Terdapat banyak penelitian lain yang berhubungan dengan ketidaktepatan kode diagnosis (Windari and Kristijono, 2016a), (Rusliyanti, 2016), (Ayu and Ernawati, 2012).

Data dalam rekam medis dapat digunakan sebagai bahan deteksi potensi fraud, melalui telusur kode diagnosis dan telusur clinical pathway melalui rekaman pelayanan kesehatan yang dilakukan oleh tenaga kesehatan.
Clinical pathway (CP) merupakan rangkumanseluruh langkah pelayanan kesehatan terpadu (Fallis, 2013). Keberadaan $C P$ dapat menjadi kendali mutu dan kendali biaya terutama di era BPJS, (Paramita and Dwiprehasto, 2019), (Wardhana, Rahayu and Triguno, 2019).

Hasil observasi dokumen clinical pathway di RSU S hanya terdapat 7 dokumen yaitu CP kasus; Bronkopneumonia, Stroke Non Haemoragic (I64), Post Op Appendicitis, Delivery by Caesarean section, unspecified, Benign Prostate Hyperplasia, Post Of Fraktur Collum Femur, Demam Typhoid. Demam Typhoid dipilih karena merupakan kasus yang sudah memiliki CP dan paling banyak diklaimkan. Terdapat banyak kasus yang lebih banyak klaimnya dari kasus Typhoid, hanya belum memiliki CP.

Tujuan penelitian ini adalah menelusuri potensi fraud dalam rekam medis melalui telusur keakuratan kode diagnosis yang mempengaruhi klaim dan telusur clinical pathway. Studi kasus pada penyakit Thypoid.

\section{METODE}

Jenis penelitian studi kasusdengan pendekatan kuantitatif kualitatif. Penelitian dilaksanakan di RSU S. RSU S adalah rumah sakit rujukan di daerah priangan timur.

Subjek penelitian dipilih secara purposive sampling. Subyek penelitian ini adalah petugas yang tergabung dalam tim pencegahan fraud dan koder. Sampel penelitian kuantitatif menggunakan rekam medis untuk mengetahui ketepatan koding diagnosis. Populasi penelitian diambil dari TXT BPJS. Data SIMRS di RSU Sbelum terintegrasi, sehingga agak sulit untuk ditelusuri. Pengumpulan data dilakukan dengan observasi menggunakan lembar observasi terhadap rekam medis dilihat dari ketepatan diaganosis serta mencocokkan dengan clincal pathway. Selanjutnya observasi dan penelusuran biaya klaim. Wawancara 
mendalam (indepth interview) kepada koder dan tim pencegahan fraud. Selanjutnya, dilakukan analisis deskriptif dan analisis konten.

\section{HASIL DAN PEMBAHASAN}

\section{Akurasi koding diagnosis}

Tabel 1. Presentase ketepatan kode diagnosis RSU S

\begin{tabular}{ccccc}
\hline \multicolumn{6}{c}{ Ketepatan Kode Diagnosis } \\
\hline \multirow{2}{*}{ Kode Diagnosis } & \multicolumn{3}{c}{ Tepat } & \multicolumn{3}{c}{ Tidak Tepat } \\
\cline { 2 - 5 } & $\mathbf{n}$ & $\mathbf{\%}$ & $\mathbf{n}$ & $\mathbf{\%}$ \\
\hline A01.0 & 60 & 68,97 & 27 & 31,03 \\
\hline
\end{tabular}

Berdasarkan tabel 1, dari 87 dokumen rekam medis kasus Thypoid di RSU S, ketidaktepatan kode diagnosis sebesar $31,03 \%$.

Tabel 2. Rincian ketidaktepatan kode diagnosis

\begin{tabular}{|c|c|c|c|}
\hline \multicolumn{4}{|c|}{ Perubahan Kode } \\
\hline $\begin{array}{c}\text { Kode } \\
\text { Diagnosis }\end{array}$ & $\mathbf{N}$ & $\%$ & Keterangan \\
\hline Primer & 19 & 70,37 & $\begin{array}{l}\text { Kode Thypoid menjadi } \\
\text { Suspect Thypoid, reseleksi } \\
\text { kode disentri amuba, } \\
\text { reseleksi kode efusi pleura } \\
\text { dengan TB paru }\end{array}$ \\
\hline Sekunder & 4 & 14,81 & $\begin{array}{l}\text { Reseleksi kode diare, } \\
\text { reseleksi kode riwayat } \\
\text { penyakit, penambahan kode } \\
\text { TB paru }\end{array}$ \\
\hline $\begin{array}{l}\text { Primer } \\
\text { dan } \\
\text { Sekunder }\end{array}$ & 4 & 14,81 & $\begin{array}{l}\text { Reseleksi kode Suspect } \\
\text { Thypoid dan tanda gejala, } \\
\text { reseleksi kondisi pada ibu } \\
\text { hamil }\end{array}$ \\
\hline
\end{tabular}

Berdasarkan tabel 2, dari 27 kasus dengan kode diagnosis tidak tepat, $70.37 \%$ ketidaktepatan pada diagnosis primer.

Penelusuran dokumen rekam medis menunjukkan jumlah total kasus dengan kode diagnosis typhoid sejumlah 146 kasus, dan dokumen yang ada di ruangan filing sejumlah 87 kasus, sisanya tidak ditemukan karena berada di gudang yang sudah tercampur dengan dokumen lain dan peneliti mengalami kesulitan untuk memisahkannya, sehingga penelitian ini menggunakan sampel sejumlah 87 kasus yang ada.
Berdasarkan tabel 1, dari 87 rekam medis kasus typhoid, ketidaktepatan kode diagnosis sebesar $31,03 \%$. Adapun rincian ketidaktepatan kode diagnosis karena terdapat 19 dokumen (70,37\%) berpotensi untuk berubah menjadi kode suspect typhoid, reseleksi kode disentri amuba, reseleksi kode efusi pleura dengan TB paru, 4 dokumen (14,81\%) berpotensi untuk berubah menjadi reseleksi kode diare, reseleksi kode riwayat penyakit, penambahan kode TB paru, reseleksi kode suspect typhoid dan tanda gejala, dan 4 dokumen $(14,81 \%)$ berpotensi untuk berubah menjadi reseleksi kondisi pada ibu hamil (lihat tabel2).

Penegakan kode diagnosis typhoid, sebetulnya sudah berdasarkanbuku ICD 10. Terdapat aturan dalam buku ICD volume 2 halaman 126, dijelaskan bahwa "If, after an episode of health care, the main condition is still recorded as "suspected", "questionable", etc, and there is no further information or clarification, the suspected diagnosis, must be coded as if established" (WHO, 2004). Sehingga, berdasarkan aturan tersebut maka tidak ada diagnose suspect (dicurigai, dipertanyakan), bila sudah menjalani episode perawatan dan tidak ada informasi atau klarifikasi tambahan, maka dapat tegak diagnose typhoid. Kode kondisi suspectmerupakan kondisi dimana belum adanya diagnosis yang ditegakkan sampai akhir masa perawatan sehingga diagnosis utama dapat digunakan dari kode pada BAB XVIII dan XXI.

Berdasarkan hasil observasi dokumen terdapat 21 diagnosa yang berpotensi berubah dengan kode suspect, terdiri dari 19 kasus berubah hanya diagnosis primernya dan 2 kasus berubah baik diagnosis primer maupun sekundernya.Terdapat satu kasus dengan diagnosis utama dalam resume rekam medis tertulis demam typhoid dan diagnosis sekunder yaitu efusi pleura dan TB paru dan dilakukan tindakan pemasangan CTT (chest thorax tube), pada 
kasus ini diagnosis utama dapat berubah menjadi Tuberkulosis Paru Pleura (A16.5) dikarenakan tidak dilakukan pemeriksaan serologi padahal sesuai dengan Berita Acara BPJS, tes serologi harus dilakukan, tetapi pemeriksaan dan tindakan yang dilakukan merupakan terapi untuk kasus Tuberkulosis Paru Pleura, sesuai Rule MB1.

Ketika kondisi minor atau yang telah berlangsung lama, atau masalah insidental, tercatat sebagai diagnosis utama, sedangkan kondisi yang lebih berarti, relevan dengan pengobatan yang diberikan dan/atau spesialisasi perawatan, tercatat sebagai diagnosis sekunder, maka reseleksi kondisi yang berarti tersebut sebagai diagnosis utama.Kelengkapan penulisan informasi medis pada setiap formulir rekam medis memilikiperanan penting dalam menentukan keakuratan kode diagnosis yang ditetapkan oleh dokter (Maryati, Murti and Indarto, 2016).

Pada kasus yang lain, dalam resume medis tertulis typhoid sebagai diagnosis utama, tetapi pada kasus ini pasien sedang hamil sehingga kode diagnosis utama berubah menjadi kondisi kehamilan. Pada kasus kehamilan akan menggunakan diagnosis utama dengan kode O98.8, apabila tidak ada kode diagnosis lainnya.

Kasus lainnya, dalam resume medis tertulis typhoid sebagai diagnosis utama dan diare serta impetigo sebagai diagnosis primer, adapun pengkodean diare sebagai diagnosis sekunder dapat direseleksi sesuai aturan BA tahun 2018 halaman 2, kode A09 seharusnya tidak dikoding lagi apabila sudah ada typhoid fever (A01.0) yang tegak secara medis. Tidak ada instruksi khusus untuk menggabungkan antara A01.0 dengan A09 menjadi salmonella, enteritis (A02.0) dari buku ICD baik volume I maupun III. Pada kasus lain terdapat perbedaan kode diagnosis antara resume dan klaim BPJS, dalam resume medis pasien tertulis diagnose disentri amoeba dan hasil pemeriksaan penunjang ditemukan amoeba pada feses pasien, diduga terjadi kesalahan membaca tulisan dokter oleh koder saat melakukan kodefikasi (hasil konfirmasi dalam wawancara dengan koder menyatakan ada kemungkinan salah membaca diagnosis dikarenakan tulisan dokter yang sulit dibaca).

Penyimpanan dokumen rekam medis yang masih belum baik, menyebabkan masih banyakdokumen yang tercecer dan belum diketahui keberadaannya, bisa jadi dokumen hilang. Salah satu fungsi sekunder dari rekam medis adalah aspek medicolegal dan sumber clinical audit, akan terganggu dengan penyimpanan yang belum baik (Mann and Williams, 2003). Direktur rumah sakit bertanggung jawab atas rekam medis. Ketentuan menyimpan rekam medis ini diwajibkan oleh peraturan perundang-undangan dan setiap kehilangan atau kerusakan menjadi tanggung jawab pimpinan rumah sakit. Peraturan perundang-undangan ini merupakan hukum positif yang wajib dilaksanakan.

Ketidakakuratan kode diagnosis, berdasarkan hasil wawancara, terjadi karena perbedaan aturan dalam menegakkan kode diagnosis untuk klaim BPJS yang memiliki aturan tersendiri. Peran verifikator BPJS menjadi sangat penting, ketika melaksanakan verifikasi berkas klaim, klaim yang lolos yang hanya dapat dibayarkan oleh BPJS. Pentingnya bagi verifikator untuk dapat menetapkan jumlah kasus yang disampel dalam melakukan verifikasi, agar perkiraan ketepatan kode sesuai dengan aturan dalam Berita Acara BPJS.

Seluruh populasi dilakukan verifikasi dan rumah sakit tidak dirugikan bila di kemudian hari ada audit pasca klaim, apabila sudah diperiksa oleh verifikator, dan kesalahan verifikasi menjadi tanggung jawab BPJS, dalam hal ini karena petugas atau verifikator merupakan pegawai BPJS. Ketidaksesuaian kode langsung diputuskan dan disepakati sesuai aturan yang ada. Audit internal 
memang diperlukan, tetapi verifikator juga bertanggung jawab dengan hasil audit. Audit internal adalah bagian integral dari organisasi, jika difungsikan secara optimal dan berisi orang-orang yang berintegritas dan obyektif maka akan efektif dalam upaya pencegahan fraud (Dewi, 2017).

Penegakan aturan dalam melakukan pengkodean seharusnya lebih konsisten dan disosialisasikan. Idealnya aturan berlaku sama untuk dokumentasi maupun untuk kepentingan klaim. Terdapat perbedaan antara kode diagnosis versi ICD 10 dengan kode untuk klaim ke BPJS karena adanya Berita Acara (BA) BPJS yang sering dirubah dan diupdatedan Peraturan Menteri Kesehatan 76 tahun 2016 tentang Pedoman Indonesian Case Base Groups (INA-CBG). BA yang dimaksud terakhir dikeluarkan adalah Berita Acara Kesepakatan Bersama Panduan Penatalaksanaan Solusi Permasalahan Klaim INA CBG Tahun 2018.

Berita Acara berdasarkan hasil wawancara dengan koder, sering mendadakdisampaikan, dan sosialisasi hanya melalui grup whatsapp, sehingga kadang-kadang ada aturan yang belum diketahui atau belum dipahami. Perbedaan interpretasi kode maupun penambahan kode diagnosis sekunder dapat merubah pola tarif, seperti pada kasus penyakit typhoid. Jadi kesulitan pada informasi BA, sehingga tafsirnya kadangkala berbeda setiap rumah sakit. Terdapat kasus yang lolos di rumah sakit satu belum tentu lolos klaim di rumah sakit lainnya, padahal dengan aturan BA yang sama.

Potensi fraud bukan hanya upcoding, tapi bisa juga undercoding, tetapi seringkali tidak disengaja karena kesalahan entry atau kesulitan koder membaca tulisan dokter. Ketidaktepatan koding, salah satunya karena tulisan diagnosis dan tindakan medis dokter belum seluruhnya dapat dibaca (Windari and Kristijono, 2016b). Undercoding dapat terjadi pada kasus-kasus yang tidak sesuai BA, misalnya pada kasus pasien yang masuk IGD tapi bukan kasus gawat darurat atau kasus-kasus yang diharuskan aturan BA rawat jalan, padahal kenyataannya dokter mengharuskan rawat inap. Sehingga potensi kerugian dapat terjadi juga di rumah sakit.

\section{Telusur Biaya Klaim Sesuai Koding Diagnosis}

Tabel 3. Presentase kesesuaian tarif RSU S

\begin{tabular}{ccc}
\hline \multicolumn{3}{c}{ Kesesuaian Tarif RSU S } \\
\hline Tarif & $\mathbf{n}$ & $\mathbf{\%}$ \\
\hline Sesuai & 64 & 73,56 \\
Tidak Sesuai & 23 & 26,44 \\
\hline
\end{tabular}

Berdasarkan tabel 3, dari 87 rekam medis kasus demam tifoid, dengan presentase ketidaksesuaian tarif klaim BPJS di RSU S sebesar 26,44\%.

Tabel 4. Perubahan Tarif Klaim BPJS di RSU S

\begin{tabular}{ccc}
\hline \multicolumn{3}{c}{ Perubahan Tarif } \\
\hline Tarif & $\mathbf{n}$ & $\mathbf{\%}$ \\
\hline Naik & 21 & 91,30 \\
Turun & 2 & 8,70 \\
\hline
\end{tabular}

Berdasarkan tabel 4, sebanyak $91.30 \%$ ketidaksesuaian merupakan tarif klaim naik atau lebih mahal dari kode sebelumnya.

INA-CBG memuat 1077 kelompok tarif yang terdiri dari 789 tarif pelayanan rawat inap dan 288 tarif pelayanan rawat jalan dengan dasar pengelompokan menggunakan ICD 10 edisi 2010 untuk diagnosis dan ICD 9 CM edisi 2010 untuk tindakan. Oleh karena itu kode diagnosis sertakode tindakan akan menentukan besaran tarif yang dibayarkan. Berdasarkan hasil penelitian terdapat kemungkinan perubahan kode diagnosis. Perubahan kode diagnosis akan otomatis merubah besaran tarif dapat naik atau turun.

Berdasarkan tabel 4 dari 87 rekam medis kasus demam typhoid, dengan presentase ketidaksesuaian tarif klaim 
BPJS sebesar $26,44 \%$ atau 23 kasus. Sebanyak 21 kasus (91.30\%) ketidaksesuaian merupakan tarif klaim naik atau lebih mahal dari seharusnya yaitu untuk kode demam typhoid A01.0 yang tidak dilakukan tes serologi seharusnya dikode Z03.8 suspecttyphoid. Penyebab terbesar kesenjangan tarif adalah pelayanan obat dan penggunaan sumber daya laboratorium yang tidak efisien (Indriani et al., 2013).

Terdapat 2 kasus dengan tarif yang dibayarkan lebih murah yaitu kasus demam typhoid dengan diagnosis Tuberculosis Pleura dengan tindakan CTT seharusnya kode Tuberculosis Pleura A16.5 menjadi diagnosis utama dan pada kasus lain pada dokumen rekam medis tertulis demam typhoid sebagai diagnosis primer dan tuberculosis A16.0 sebagai diagnose sekunder tetapi hanya diagnosis demam typhoid A01.0 yang diklaimkan padahal dalam dokumen rekam medis tercatat pula terapi tuberculosisnya.

Alasan kenapa di RSU S tersebut, jumlah ketidaktepatan diagnosa ada 27 kasus sementara ketidaksesuaian tarif ada 23 kasus dikarenakan pada 4 kasus tersebut dengan atau tanpa diagnosa sekunder dimasukkan tidak mempengaruhi tarif gruping klaim BPJS. Satu studi memperkirakan bahwa pengkodean yang tidak akurat dapat menyebabkan kerugian hingga 10\% dari keuntungan rumah sakit (Burns et al., 2012).

\section{Pelaksanaan clinical pathway kasus typhoid}

Berdasarkan tabel 5, dari 87 kasus demam typhoid, ketidaksesuaian pelaksanaan clinical pathway paling banyak terdapat pada item tes widal dengan presentase $21.84 \%$. Tes widal merupakan salah satu penegak diagnosis typhoidyang cepat dan mudah di daerah dengan fasilitas pelayanan kesehatan terbatas.
Tabel 5. Presentase pelaksanaan Clinical Pathway Kasus Typhoid

\begin{tabular}{rlcccc}
\hline \multirow{2}{*}{ No } & \multirow{2}{*}{ Pernyataan } & \multicolumn{2}{c}{ Sesuai } & \multicolumn{3}{c}{ Tidak Sesuai } \\
\cline { 2 - 6 } & & $\mathbf{N}$ & $\mathbf{\%}$ & $\mathbf{N}$ & \% \\
\hline 1 & Terdapat Hasil & 87 & 100 & & \\
& Pemeriksaan & & & & \\
& Dokter (dokter jaga/ & & & & \\
& dokter Sp.PD) & & & & \\
2 & Tes Widal & 68 & 78,16 & 19 & 21,84 \\
3 & Infus & 87 & 100 & & \\
4 & Obat & 87 & 100 & & \\
5 & Nutrisi & 84 & 96,55 & 3 & 3,45 \\
6 & Instruksi & 80 & 91,95 & 7 & 8,05 \\
& Mobilisasi & 87 & 96,55 & 3 & 3,45 \\
7 & Tanda-tanda Vital & 86 & 98,85 & 2 & 1,15 \\
8 & Intale/Output & 1 & 100 & & \\
9 & Informed Consent & 84 & 96,55 & 3 & 3,45 \\
10 & Edukasi & 84 & 96,55 & 3 & 3,45 \\
11 & Penjelasan & 87 & 100 & & \\
12 & Persiapan Pulang & & & & \\
& Autentikasi & & & & \\
\hline
\end{tabular}

Pelayanan kesehatan memenuhi standar pelayanan Kesehatan/kedokteran (Kementerian Kesehatan RI., 2010), yang meliputi Pedoman Nasional Pelayanan Kedokteran (PNPK) dan Standar Prosedur Operasional (SPO). SPO disusun dalam bentuk Panduan Praktik Klinis (clinical practice guidelines) yang dapat dilengkapi dengan clinical pathway, algoritme, protokol, prosedur atau standing order. CP dapat meningkatkan mutu pelayanan (Pinzon, Asanti and Widyo, 2009). CP mampu memberikan penurunan biaya perawatan (Iroth, Ahmad and Pinzon, 2017).

Hasil observasi dokumen clinical pathway di RSU S hanya terdapat 7 dokumen yaitu CP kasus; Bronkopneumonia, Stroke Non Haemoragic (I64), Post Op Appendicitis, Delivery by Caesarean section, unspecified, Benign Prostate Hyperplasia, Post Of Fraktur Collum Femur, dan Demam Typhoid. Clinical Pathway merupakan tools untuk mendukung pengambilan keputusan klinis dalam menyediakan proses perawatan standar (Cho et al., 2020). Keberadaanya sangat penting dalam pelayanan kesehatan.

Hasil observasi kesesuaian dengan clinical pathway kasus typhoid adalah sebagai berikut; dari 87 kasus typhoid pelaksanaan tes widal sesuai clinical 
pathway untuk penegakan diagnosis typhoid sebanyak 94,25\% atau 82 kasus dan $5,75 \%$ atau sebanyak 5 kasus tidak melakukan tes widal. Hal ini telah diklarifikasi dalam wawancara kepada petugas koder, didapatkan informasi bahwa apabila terdapat keluhan deman yang lama pada pasien yang datang ke rumah sakit maka tes widal biasanya tidak dilakukan dengan alasan hasil tes akan negatif.

Pelaksanaan clinical pathway, item pemberian nutrisi sebanyak $96,55 \%$ atau 84 kasus, dan sebanyak $3,45 \%$ atau 3 kasus pemberian nutrisi tidak terdokumentasikan. Pelaksanaan clinical pathway, item intruksi mobilisasi sebanyak $91,95 \%$ atau sebanyak 80 kasus, dan sebanyak $8,05 \%$ atau sebanyak 7 kasus intruksi mobilisasi tidak terdokumentasikan dalam asuhan keperawatan pasien. Pelaksanaan clinical pathway, item tanda-tanda vital sebesar $96,55 \%$ atau 84 kasus dan $3,45 \%$ atau sebanyak 3 kasus atau 3,45\% tidak ditemukan hasil pemeriksaan tanda-tanda vital.

Pelaksanaan clinical pathway, item intake/output sebesar $98,85 \%$ atau sebanyak 86 kasus, dan $1,15 \%$ atau sebanyak 2 kasus tidak tercantum intake/ output. Pelaksanaan clinical pathway, item edukasi dan penjelasan persiapan pulang sebesar $96,55 \%$ atau 84 kasus dan 3,45\% atau 3 kasus edukasi dan penjelasan persiapan pulang tidak diisi. Adapun item autentifikasi sudah dilaksanakan $100 \%$.

Kasus typhoid tahun 2018 sudah lolos dari pemeriksaan verifikator BPJS. Terdapat 19 kasus yang tidak dilakukan tes serologi, sehingga kemudian berubah menjadi diagnose suspect. Hasil wawancara, koder menyebutkan bahwa ada kasus yang sudah melakukan klarifikasi ke dokter yang bersangkutan, dan dokter secara klinis meyatakan bahwa diagnosanya tetap tegak demam typhoid. Sedangkan penjelasan lainnya bahwa tes widal (salah satu jenis tes serologi) sudah dilakukan di FKTP tetapi hasil pemeriksaan tidak terlampir.

Item informed consent hanya 1 kasus karena hanya terjadi di kasus typhoid dengan Efusi Pleura dan dilakukan tindakan CTT. Sedangkan item kesesuaian CP lainnya menunjukkan ketidaklengkapan pengisian dokumen rekam medis, sehingga ada beberapa yang masih tidak terisi tetapi kemungkinan sudah dilaksanakan. Faktor paling signifikan yang mendasari kesalahan pengkodean diagnosis adalah rendahnya kualitas pendokumentasian rekam medis (Maryati, Murti and Indarto, 2016).

\section{PENUTUP}

Fraud berpotensi terjadi di rumah sakit, karena ketidaktepatan koding sehingga menjadi upcoding. Upcoding tidak selalu disebut fraud, harus ada unsur kesengajaan untuk mendatangkan keuntungan finansial. Upcoding dapat merubah klaim menjadi lebih tinggi. Hal ini disebabkan karena perbedaaan kode diagnosis berdasarkan ICD 10 dan kode yang digunakan untuk pelaksanaan klaim yang mengacu pada peraturan yang dibuat oleh BPJS. Pencegahan terjadinya upcoding ini dengan melakukan verifikasi yang tepat dari petugas verifikator yang menerima berkas klaim terhadap semua dokumen. Keberadaan clinical pathway juga memiliki peran penting dalam pelayanan kesehatan. Clincal pathway dapat dapat meningkatkan efisiensi dan efektifitas mutu pelayanan kesehatan.

\section{DAFTAR PUSTAKA}

Ayu, R. D. V. and Ernawati, D. (2012) 'Tinjauan Penulisan Diagnosis Utama dan Ketepatan Kode ICD-10 pada Pasien Umum di RSUD Kota Semarang Triwulan I', UDiNus Repository, p. 14.

BPJS Kesehatan (2015) 'Tindak Kecurangan (Fraud) Merugikan Program JKN (Negara)', Info BPJS Kesehatan, (November), p. 12. 
Burns, E. M. et al. (2012) 'Systematic review of discharge coding accuracy', Journal of Public Health, pp. 138-148. doi: 10.1093/pubmed/fdr054.

Cho, M. et al. (2020) 'Developing datadriven clinical pathways using electronic health records: The cases of total laparoscopic hysterectomy and rotator cuff tears', International Journal of Medical Informatics, 133. doi: 10.1016/ j.ijmedinf.2019.104015.

Djasri, H., Rahma, P. A. and Hasri, E. T. (2016) 'Korupsi Dalam Pelayanan Kesehatan Di Era Jaminan Kesehatan Nasional: Kajian Besarnya Potensi Dan Sistem Pengendalian Fraud', Integritas, pp. 113-133. Available at: https://jurnal.kpk.go.id/Dokumen/ jurnal-integritas-volume-02-nomor-1tahun-2016/jurnal-integritas-volume02-nomor-1-tahun-2016 - 06.pdf.

Fallis, A. . (2013) 'Konsep CLinical Pathway', Journal of Chemical Information and Modeling, 53(9), pp. 1689-1699.

Indriani, D. et al. (2013) 'Dampak Biaya Laboratorium Terhadap Kesenjangan Tarif INA-CBGs dan Biaya Riil Diagnosis Leukemia', Kesmas: National Public Health Journal, 7(10), p. 440. doi: 10.21109/kesmas.v7i10.2.

Iroth, J. S., Ahmad, R. A. and Pinzon, R. (2017) 'Dampak Penerapan Clinical Pathway Terhadap Biaya Perawatan Pasien Stroke Iskemik Akut Di Rs Bethesda Yogyakarta', Berkala Ilmiah Kedokteran Duta Wacana, 2(1), p. 267. doi: 10.21460/bikdw.v2i1.38

Jones, B. and Jing, A. (2011) 'Prevention not cure in tackling health-care fraud.', Bulletin of the World Health Organization, 89(12), pp. 858-859. doi: 10.2471/blt.11.021211

Karimah, R. N., Setiawan, D. and Nurmalia, P. S. (2016) 'Diagnosis Code Accuracy Analysis Of Acute Gastroenteritis Disease Based on Medical Record Document in Balung Hospital Jember', Journal of
Agromedicine and Medical Sciences, 2(2), p. 12. doi: 10.19184/ams.v2i2.2775.

Kemenkes (2019) 'Berita Negara', Menteri Kesehatan Republik Indonesia Peraturan Menteri Kesehatan Republik Indonesia, Nomor 44(879), pp. 2004-2006.

Kementerian Kesehatan RI. (2010) 'Peraturan Menteri Kesehatan Nomor 1438/Menkes/Per/IX/2010 tentang Standar Pelayanan Kedokteran'.

KSI (2016) 'Stop Fraud di Dunia Kesehatan', Knowledge Sector Initiative.

Mann, R. and Williams, J. (2003) 'Standards in Medical Record Keeping', Clin Med (Lond), Jul-Aug;3(, pp. 329-32. doi: 10.7861/ clinmedicine.3-4-329.

Maryati, W., Murti, B. and Indarto, D. (2016) 'Factors Affecting the Quality of Diagnosis Coding and Medical Record at Dr. Moewardi Hospital, Surakarta', Journal of Health Policy and Management, 01(02), pp. 61-70. doi: 10.26911/thejhpm.2016.01.02.01.

Paramita, O. D. and Dwiprehasto, I. (2019) 'Penggunaan Clinical Reminder Sebagai Instrumen Kendali Mutu dan Kendali Biaya Pada Penatalaksanaan Bayi Prematur Yang Dirawat di NICU RSUD Tarakan'. Yogyakarta. Available at: http://etd.repository.ugm.ac.id/ penelitian/detail/170936.

Pinzon, R., Asanti, L. and Widyo SMF Saraf Bethesda Yogyakarta, K. R. (2009) 'Clinical Pathway Dalam Pelayanan Stroke Akut: Apakah Pathway Memperbaiki Proses Pelayanan?', Jurnal Manajemen Pelayanan Kesehatan, 12(1), pp. 20-23.

Puspitasari, N. and Kusumawati, D. R. (2017) 'Evaluasi Tingkat Ketidaktepatan Pemberian Kode Diagnosis Dan Faktor Penyebab Di Rumah Sakit X Jawa Timur', Jurnal Manajemen Kesehatan Yayasan RS.Dr. Soetomo, 3(2), p. 158. doi: 10.29241/ jmk.v3i1.77

Ravelo, J. L. (2019) 'WHO fraud, harassment cases on the rise', pp. 2017- 
2019.

Rusliyanti, D. (2016) 'Analisis Ketepatan Pengkodean Diagnosis Berdasarkan ICD-10 dengan Penerapan Karakter Ke-5 pada Pasien Fraktur Rawat Jalan Semster II di RSU Mitra Paramedika Yogyakarta', Jurnal Permata Indonesia, 7(1), pp. 26-34. Available at: http:// www.permataindonesia.ac.id/wpcontent/uploads/2016/08/03.-JurnalPI_Lusi-Anas-Harinto.pdf.

Wardhana, A., Rahayu, S. and Triguno, A. (2019) 'Implementasi Clinical Pathway Tahun 2018 dalam Upaya Meningkatkan Mutu Pelayanan di Rumah Sakit Umum Daerah Koja Implementation of 2018 Clinical Pathway in Efforts to Increase the
Quality of Service in the Koja Regional General Hospital', 6(1), pp. 45-53.

WHO (2004) 'ICD-10: International Statistical Classification of Diseases and Related Health Problems: Ttenth Revision. - 2nd ed', in, p. 131.

Windari, A. and Kristijono, A. (2016a) 'Analisis Ketepatan Koding yang Dihasilkan Koder di RSUD Ungaran', Jurnal Riset Kesehatan, 5(1), pp. 35-39. Available at: http://ejournal.poltekkessmg.ac.id/ojs/index.php/jrk.

Windari, A. and Kristijono, A. (2016b) 'Analisis Ketepatan Koding yang Dihasilkan Koder di RSUD Ungaran', Jurnal Riset Kesehatan, pp. 35-39. Available at: http://ejournal.poltekkessmg.ac.id/ojs/index.php/jrk. 